\title{
The Stock Market Efficiency of Emerging Markets: Evidence from Asian Region
}

\author{
Kasilingam Lingaraja ${ }^{1}$, Murugesan Selvam ${ }^{1} \&$ Vinayagamoorthi Vasanth ${ }^{1}$ \\ ${ }^{1}$ Department of Commerce and Financial Studies, Bharathidasan University, Tiruchirappalli, Tamil Nadu, India \\ Correspondence: Kasilingam Lingaraja, Ph.D Research Scholar in Management, Department of Commerce and \\ Financial Studies, Bharathidasan University, Tiruchirappalli, Tamil Nadu, India. Tel: 91-097-9038-1933. E-mail: \\ klingarajaphd@gmail.com
}

Received: July 14, 2013 Accepted: July 21, 2014 Online Published: September 29, 2014

doi:10.5539/ass.v10n19p158 URL: http://dx.doi.org/10.5539/ass.v10n19p158

\begin{abstract}
This research paper investigates the efficiency of stock market and volatility behavior of eight Asian Emerging market indices. This study used the secondary daily time series data for the period of ten years from 01-01-2004 to 31-12-2013. The Econometric models (GARCH, Autocorrelation and Runs Test) where used to test the volatility and market efficiency of Asian emerging stock markets. Besides, the long run relationship was studied. The Hypotheses about the importance of different channels are tested .This paper provides significant evidences of market efficiency and randomness distribution in these emerging Asian markets. The findings of this study will be useful for investing Community, Government and Policy Regulators in these sample countries.
\end{abstract}

Keywords: volatility behavior, Asian emerging stock markets, GARCH $(1,1)$ model, autocorrelation, runs test, market efficiency, government policy makers

JEL Classification Code: C22; G14; G15; F30.

\section{Introduction}

The purpose of this study is to inspect the efficiency of emerging markets of Asia. An efficient market provides on continues basis a platform no opportunities to engage in profitable trading activities. If a market is not efficient, the regulatory authorities normally take necessary steps to ensure that the stocks are correctly priced leading to stock market efficiency. The efficiency of emerging markets is characterized by regular and unexpected changes in variance. It is to be noted that national and international events in the countries pave way for high volatility are found during the periods. This paper examines whether international or national events in emerging stock market are more important in causing major shifts in markets' volatility /efficiency in Asian region. In this paper, four sections are structured as follows. Section -1.1 describes the emerging stock markets. Section- 2 outlines the review of literature and research design. Section- 3 illustrates the samples and summarizes the preliminary analysis results. Section -4 concludes the paper.

\subsection{Emerging Stock Markets}

The emerging market consists of retail investors and other stake holders who would be expected to earn higher returns for their investments but accompanied by greater desire for risk. The global index providers sometimes include in this category relatively wealthy countries (www.investopedia.com).

In 1988, the Morgan Stanley Capital International (MSCI) (Note 1) launched the first comprehensive emerging markets index. Since then, emerging markets Index has become an important and integrated part of a global equity portfolio allocation. Besides, US Department of Commerce (Note 2) also launched the emerging market index in the similar way. The list of emerging stock markets in the world is given in Figure 1 (as identified by MSCI). According to the criteria adopted by the Morgan Stanley Capital International (MSCI), the world emerging stock markets are grouped into three categories -Americas, Europe, Middle East \& Africa and Asia.

It is clear that there are five markets in America continent, eight markets in Europe and Middle East \& Africa continents and eight markets in Asian continents. The present study used only eight emerging markets of Asian region, namely, Shanghai Stock Exchange Composite Index (China), NSE Nifty (India), Jakarta Composite Index (Indonesia), Kospi Index (Korea), KLSE (Malaysia), Philippine stock Index (Philippines), TSEC weighted Index (Taiwan), and SET Index (Thailand). 


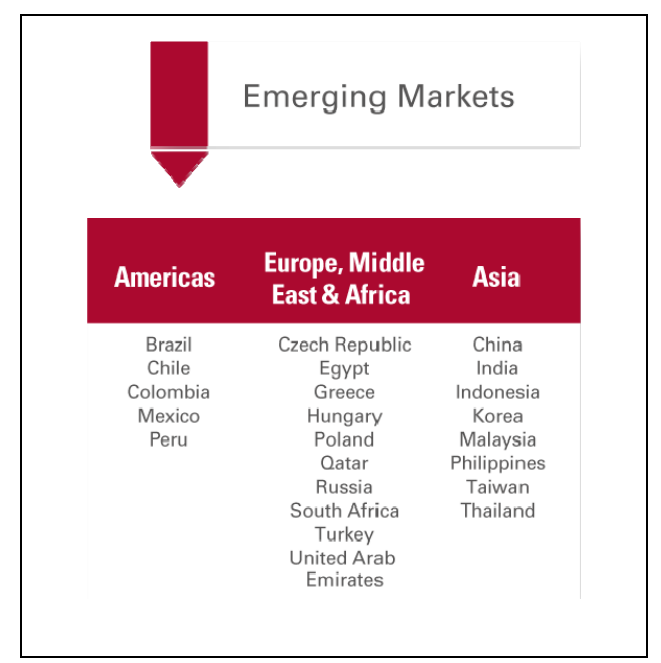

Figure 1. List of Emerging Markets

Source: Developed from Morgan Stanley Capital International (MSCI) (Retrieved on 20.06.2014)

\section{Review of Literature and Research Design}

This section describes the relevant reviews relating to efficiency of emerging stock markets and also explains the research design covering statement of the problems, Needs of the study, Objectives, Hypothesis, Methodology, Feedback and Limitations of the study. An attempt has been made to review the earlier research works undertaken in the area of efficiency and stock market volatility among emerging Asian stock markets to understand research gaps, tools used and findings of earlier studies.

Taufiq Choudhry (1996) studied the impact of 1987 stock market crash and the persistence of volatility in six sample emerging stock markets before and after the 1987 stock market crash. It was found that the existence of shocks to volatility was permanent before the crash and temporary after the crash in Mexico and Thailand while the reverse was true for Greece and India. Angela Ng (2000) examined the magnitude and changing nature of volatility spillovers from Japan and the US to six Pacific-Basin equity markets. It is found that the return volatility in the Pacific-Basin markets may be driven by some forces that are specific to this particular region but unrelated to the Japanese market. Juncal Cunado Eizaguirre (2004) identified the various factors that cause stock market volatility. An attempt was made to study the alternative methodologies to analyze whether the volatility of the Spanish stock market had changed significantly over the study period from 1941 to 2001 . The results clearly showed that growth in trading volume recorded significant impact on stock market volatility, although this relationship was stable through the years. Giulio Cifarellia and Giovanna Paladino (2005) investigated the high frequency behavior of US, British and German stock market exuberance, using an index provided by standard portfolio arbitrage relationships. For the purpose of analysis of this study, symmetric and asymmetric multivariate GARCH models were applied to quantify volatility (international) linkages among the sample countries' stock markets. It was found that the equity markets volatility modeling with exuberance indexes was more accurate than modeling with stock returns. Selvam Murugesan et al (2007) discussed the dynamic behavior of stock index returns of sample markets of Asia Pacific Countries (Japan, Hong Kong, India, Korea, China, Taiwan, Singapore, Malaysia, Thailand and Indonesia) during the period of one year from January 2006 to December 2006. This study found evidence of time varying volatility, clustering, high persistence and predictability for almost all the Asian market indices. They also examined the emerging markets except India and China, which exhibited low returns. Panayiotis F. Diamandis (2008) studied the dynamic behaviour of stock market volatility for four sample Latin American stock markets (i.e., Argentina, Brazil, Chile and Mexico). The mature stock market of US had changed during the last two decades. Ping Wang and Mike Theobald (2008) investigated regime-switching behaviour in the process of return-generation in the six East Asian emerging stock markets. The study also examined the specific characteristics of each regime by using Markov-switching variance models. It was found that financial liberalization had made the Indonesian, Korean and Thai markets more vulnerable to foreign investments while the stock markets like Malaysia, the Philippines and Taiwan were not affected by the openness of financial markets. Thomas Lagoarde-Segot and Brian M. Lucey (2008) examined the informational efficiency of seven emerging Middle-Eastern North African (MENA) stock markets. The study found that the extent of weak-form efficiency in the MENA stock markets was primarily explained by 
differences in stock market size. Fazeel M. Jaleel and Lalith P. Samarakoon (2009) studied the impact of liberalization of the Sri Lankan stock market on return volatility. This study found that liberalization of the financial market to foreign investors had significantly increased the volatility of return in the Colombo Stock Exchange. Both under conditional and unconditional measures, the volatility were the highest during the liberalization period. Queensly Jeyanthi. B. J and M. Albert William SJ (2009) in this study was conducted a long term analysis of the active relationship between Asian countries like India, Japanese, Singapore and developed U.S.A stock markets were used during the study period from April 2000 to March 2008. The econometric tools like Unit Root Tests, Cross - Correlation Test, ADF and Cointegration Test were applied to test the relationship. The result reveals that the Indian market was highly co- integrated with Singapore. But India was not properly linked from USA and Japan markets during the study period. Dimitris N. Dimitrakopoulos et al. (2010) investigated the issue of market risk quantification for emerging and developed market equity portfolios. The results of the study indicate that despite the documented differences between emerging and developed markets, the VaR models used in this study were common for both asset classes. Imen Zgueb Rejichi and Chaker Aloui (2012) evolved the efficiency of MENA stock markets. It was noted that the empirical investigation was conducted on the major Middle East and North African stock markets. According to Anita Plesoianu et al. (2012), the investigation of multifractal analysis was performed upon the intra daily and the daily time series of BET index, BET-C index. The ten stocks, listed on the Bucharest Stock Exchange, assessed the degree of informational efficiency of the Romanian Stock Market. The results of the intraday and daily return series of BET index, BET-C index and ten sample stocks listed in the Bucharest Stock Exchange revealed low degree of efficiency. David Blitz et al. (2013) scrutinized the empirical relation between risk and return in emerging equity markets. It is found that the low correlations between the volatility effects in emerging and developed equity markets, which argue against a common-factor explanation. Aymen Ben Rejeb and Adel Boughrara (2013) studied the impact of financial liberalization on the degree of informational efficiency in emerging stock markets while considering three types of financial crises, i.e. banking, currency and twin crises. It is to be noted that emerging markets are characterized by a greater efficiency in recent years. Ching Mun Lim and Siok Kun Sek (2013) examined the volatility of stock market in Malaysia. It is to be noted that the GARCH type models (symmetric and asymmetric GARCH) were used to test the volatility of stock market in Malaysia and also used to test the performances was compared based on three statistical error measures tools, i.e. mean squared error, root means squared error and mean absolute percentage error for in sample and out sample analyses. Gilbert V. Nartea and JiWu (2013) investigated in an emerging market, the time-series behaviour of total and idiosyncratic volatility and their respective relationship with cross-sectional stock returns. It was found that the time-series behaviour of total and idiosyncratic volatility of return was episodic rather than exhibiting a long-term trend. Luis A. Gil-Alana et al. (2014) examined the statistical properties of several stock market indices in Europe, the US and Asia by means of determining the degree of dependence in both the level and the volatility of the processes. It is noted that in respect of sample indices (FTSE, Dax, Hang Seng and STI) considered for this study, there was a higher degree of dependence at both the level and the volatility during the bull periods. Kasilingam Lingaraja et al. (2014) in their study were focused on eight Asian emerging markets and one developed market like Singapore was used. It is to be noted that inter linkages and co-movements were tested by using 12 years time series data (01/01/2002 to 31/12/2013). This study was suggested and help to the investors making efficient decisions for investment in the indices of emerging stock markets in Asia. Syed Aun R. Rizvi et al. (2014) made a comparative analysis of Islamic and developed countries' markets by extending the understanding of their multi-fractal nature. It is interesting that the markets in Islamic countries have shown signs of higher efficiency, which is a positive omen for the development of the financial sector as well as the growth of the economy.

The above literature provides an overview of some empirical studies already undertaken on the same lines of the present Research. But only few studies focused the efficiency of emerging markets. Therefore, the present study is an attempt to investigate the efficiency of emerging stock market indices in Asia.

\subsection{Statement of the Problem}

The investments in emerging stock markets involve extensive risk with the possible for extraordinary returns. The investment in emerging stock markets is considered as risky as investing in developed economy and stock markets. The emerging stock markets of developing nations are typically small, with a short operating history. The emerging stock markets do exist in under developed regions of the world, which are volatile and therefore, have great growth potentials. It is to be noted that the illiquidity, corruption, political instability and currency collapse are some of the significant risk factors of emerging regions. Also, the local stock exchanges may not offer liquid markets for outside investors. The benefits of diversification from the portfolio investment in 
emerging stock markets, have become an important feature in the financial globalization, sweeping across the globe during the last two decades. Besides, the investments in emerging markets are also exposed to political phenomena that are not generally present in the more developed economies. The stock market efficiency motivates the regional as well as the global investors to invest in Emerging markets in Asian region. Hence an attempt is made to study the market efficiency of emerging markets in Asia.

\subsection{Need and Importance of the Study}

The efficiency of emerging stock market has been a major topic in finance literature. The researcher tries to find a pattern in stock return movements and the factors that determine these diversification and movements. The emerging Asian stock markets and financial institutions are vital role in the economy by channeling funds from the savers to the users. The volatility and market efficiency in the closing prices of Asian emerging stock market indices becomes process of distributing investable funds among challenging sources. The Asian emerging markets index prices fluctuations may be detrimental because such volatility may weaken the smooth functioning of the financial system and highly affect performance of the economy. This study provides a detailed analysis of equity market volatility in emerging stock markets in Asia. Besides, this research study also attempts to answer the question of why volatility is so deferent across Asian emerging stock markets. This research would help to understand the forces that character the time-series variation of volatility in eight emerging equity markets in Asia. The study of stock market efficiency of emerging Asian market indices could provide useful input to the Government, Policy regulators and the investing peoples to identify which are efficient emerging stock markets in Asia for investment.

\subsection{Objectives of the Study}

The main objective of this study is to examine the market efficiency of Emerging Stock market in Asia.

\subsection{Hypothesis of the Study}

The following hypotheses were put to test the above objective.

NH1 There is no normal distribution among the Indices of Emerging Stock Markets in Asia.

NH2 There is no stationarity among the Indices of Emerging Stock Markets in Asia.

NH3 There is no volatility among the Indices of Emerging Stock Markets in Asia.

NH4 There is no weak form efficiency among the Emerging Stock Markets in Asia, and

NH5. There is no randomly distribution among the Indices of Emerging Stock Markets in Asia.

\subsection{Methodology of the Study}

\subsubsection{Period of Study}

To examine the efficiency among indices of selected emerging stock markets in Asia, the study covered a period of 10 years from 1st Jan, 2004 through 31st Dec, 2013.

\subsubsection{Sample Design}

The study focused on all the eight Asian Emerging Equity Markets as identified by the Morgan Stanley Capital International (MSCI). The study used daily returns data of the composite stock market indices of the respective emerging stock markets of Asian countries. The emerging equity market indices used in the study were Shanghai Stock Exchange Composite Index (China), NSE Nifty (India), Jakarta Composite Index (Indonesia), Kospi Index (Korea), KLSE (Malaysia), Philippine stock Index (Philippines), TSEC weighted Index (Taiwan) and SET Index (Thailand).

\subsubsection{Data Variables and Data Sources}

The details about sample indices were collected from MSCI Emerging Market Database, Yahoo Finance database (online at www.finance.yahoo.com) and website of National Stock Exchange (NSE). The other relevant data were collected from reputed books, Journals and Articles.

\subsubsection{Tools Used for Analysis}

The following tools were used for the analysis

$>$ Descriptive Statistics (to find out the normal distribution of returns of Emerging Asian Markets)

$>\mathrm{ADF}$ Test (to experiment the stationarity among the Sample Asian Markets)

$>\operatorname{GARCH}(1,1)$ Model (to investigate the Volatility among the Sample Asian Markets)

$>$ Autocorrelation Test (to analyze the weak form efficiency among the sample indices), and 
Runs Test (for inspection of Randomness among the Sample Asian Markets)

The computation of data for this study was made by using E-Views (Version 6.0) and SPSS (Version 16.0).

\subsection{Feedback}

The Experts in the field of Emerging Stock market and the officials of stock broking companies were informally contacted by the Researcher. Their views and valuable information helped the Researcher to validate the findings of efficient emerging markets in Asia. Besides, the consultations with the experts helped the Researcher to polish up the research study. Some of the suggestions offered were based on the interaction with the experts.

\subsection{Limitations of the Study}

This research study suffers from the following limitations.

a. The study was purely based on secondary data which was collected from yahoofinance.com.

b. The study was restricted to only eight emerging Asian Market Indices.

c. The study period covered only ten years from Jan, 2004 to Dec, 2013.

d. All the limitations, associated with various tools like Descriptive Statistics, Runs Test, Autocorrelation Function (ACF) Test and GARCH Model, are applicable to this study also.

\section{Econometric Analysis and Empirical Results}

This section describes the deep analysis of efficiency by using Descriptive Statistics, Unit Root Test, GARCH, Autocorrelation and Runs test.

\subsection{Descriptive Statistics for the Sample Indices of Asian Emerging Markets}

Table 1.The results of descriptive statistics for emerging Asian stock market indices returns during the study period from 01-01-2004 to 30-12-2013

\begin{tabular}{|c|c|c|c|c|c|c|c|c|}
\hline Statistics & China & India & Indonesia & Korea & Malaysia & Philippines & Taiwan & Thailand \\
\hline Mean & 0.000274 & 0.000614 & 0.000850 & 0.000464 & 0.000411 & 0.000669 & 0.000229 & 0.000303 \\
\hline Median & 0.000108 & 0.001008 & 0.001436 & 0.000885 & 0.000537 & 0.000835 & 0.000725 & 0.000638 \\
\hline Maximum & 0.094549 & 0.177441 & 0.079215 & 0.119457 & 0.219700 & 0.098178 & 0.067422 & 0.111567 \\
\hline Minimum & -0.088407 & -0.122377 & -0.103753 & -0.105705 & -0.175076 & -0.122683 & -0.066789 & -0.148395 \\
\hline Std. Dev. & 0.016542 & 0.016447 & 0.014854 & 0.014283 & 0.011232 & 0.013660 & 0.013097 & 0.014059 \\
\hline Skewness & -0.137153 & 0.042776 & -0.491516 & -0.371750 & 1.970492 & -0.511771 & -0.308286 & -0.609059 \\
\hline Kurtosis & 6.636730 & 12.821220 & 8.905373 & 9.566090 & 134.964700 & 9.582187 & 6.273394 & 13.683110 \\
\hline Jarque-Bera & 1399 & 10016 & 3645 & 4510 & 1794585 & 4520 & 1142 & 11764 \\
\hline Probability & 0.000000 & 0.000000 & 0.000000 & 0.000000 & 0.000000 & 0.000000 & 0.000000 & 0.000000 \\
\hline Observations & 2524 & 2492 & 2441 & 2479 & 2471 & 2445 & 2470 & 2442 \\
\hline $\begin{array}{c}\text { Mean return } \\
\text { (Mean X } \\
\text { observations) (\%) }\end{array}$ & 69.1576 & 153.0088 & 207.485 & 115.0256 & 101.5581 & 163.5705 & 56.563 & 73.9926 \\
\hline
\end{tabular}

Source: http://finance.yahoo.com/ and Computed using E-Views 7 Version.

Table 1 shows the results of descriptive statistics for emerging Asian stock market indices returns during the study period from 1st January 2004 to 31 st December 2013. It is clear from the above Table that during the study period, the index of Indonesia Stock Market (JKSE) earned high mean value of 0.000850 , followed by India (0.000669) and Philippines (0.000614). The values (Indonesia, India and Philippines) were greater than that of all other Asian sample indices namely Korea (0.000464), Malaysia (0.000411), Thailand (0.000303), China (0.0002784) and Taiwan (0.000229) considered for this study. It is important to note that the mean value for all the sample indices was positive which indicates the fact that all the sample indices have earned significant the return during the study period. It is to be noted that two sample indices, namely, China (SSE) and Taiwan (TWII) recorded the lowest average daily mean returns, with values of 0.000229 and 0.000274 respectively. In terms of market unpredictability as measured by the standard deviation of daily returns, only one sample country namely China assumed the highest risk value (0.016542), followed by India (0.016447), Indonesia (0.014854), Korea (0.014283), Thailand (0.014059), Philippines (0.013660), Taiwan (0.013097) and Malaysia (0.011232). This indicates the fact that there was high risk (in the order of indices, namely, SSE Composite Index, S\&P CNX Nifty, Jakarta Composite Index, Kospi Index, , SET Index, Philippine stock Index, TSEC weighted Index and KLSE). It is significant to note that high degree of risk was useful for speculators but the investors may study the 
market risk and carefully take investment decision of portfolio diversification. The analysis of skewness shows that values for all sample indices, except Malaysia (1.970492) and India (0.042776), were negative. It is significant to note from the above Table that all indices of emerging Asian markets earned values of kurtosis larger than three or high level fat-tails, which make it Leptokurtic. Besides, the Jarque-Bera (JB) values clearly implied that all the sample indices were normally distributed. In other words, all the sample indices were less volatile during the study period. In short, the distribution of return data for all the sample indices was normal. Hence the Null Hypothesis (NH1), there is no normal distribution among the Indices of Emerging Stock Markets in Asia, was rejected.

\subsection{ADF for the Sample Indices of Asian Emerging Markets}

The results of Augmented Dickey Fuller (ADF) Test for eight emerging Asian stock market indices during the study period from $01^{\text {st }}$ January 2004 to $31^{\text {st }}$ December 2013 are presented in Table 2 . It is to be noted that test critical values for all sample indices were analyzed at significant levels of $1 \%, 5 \%$ and $10 \%$. The probability (P-Value) for all the eight sample stock market indices was 0.000000 . As stated earlier, the samples of eight emerging Asian stock market indices were taken for this study includes SSE Composite Index (China), S\&P CNX Nifty (India), Jakarta Composite Index (Indonesia), Korea Stock Exchange Index - KOPSI (Korea), FTSE Bursa Malaysia - KLSE (Malaysia), Philippine Stock Index (Philippine), Taiwan Stock Exchange Index -TWII (Taiwan) and Stock Exchange of Thailand Index (Thailand). The analysis of the above Table clearly indicates that the statistical values for all sample indices were -50.0744 for China, -47.0739 for India, -44.2398 for Indonesia, -48.8085 for Korea, -61.2444 for Malaysia, -43.8114 for Philippine, -46.9854 for Taiwan and -48.778 for Thailand. On the other hand, the statistical values for all the eight sample indices were less than that of test critical values at $1 \%, 5 \%$ and $10 \%$ significant levels during the study period. Besides, the returns data for all the eight emerging Asian stock indices indicate stationarity. According to the analysis of Durbin Watson Test, the values for all sample stock market indices were nearest value of two, i.e 1.999473 for China, 1.994279 for India, 2.000742 for Indonesia, 1.999461 for Korea, 2.015293 for Malaysia, 1.998165 for Philippines, 2.000115 for Taiwan and 2.002598 for Thailand. It is proved that all sample indices were found to have stationartiy during the study period. Besides, the values of R-Squared for the sample indices were more over equal to 0.50 , i.e 0.498652 for China, 0.470982 for India, 0.445299 for Indonesia, 0.490353 for Korea, 0.603143 for Malaysia, 0.440093 for Philippines, 0.472257 for Taiwan and 0.493804 for Thailand.

The overall analysis of the ADF Test and the values of Durbin Watson of all the sample indices were equal to two and $\mathrm{R}-$ Squared values are nearest with value of 0.50 . So, it is confirmed that there was stationarity in the returns data of all eight Asian emerging market indices. Hence, the Null Hypothesis (NH2), there is no stationarity among the Indices of Emerging Stock Markets in Asia, is rejected.

Table 2. The results of ADF for emerging Asian stock market indices returns during the study period from 01-01-2004 to 30-12-2013

\begin{tabular}{|c|c|c|c|c|c|c|c|}
\hline \multirow{3}{*}{$\begin{array}{r}\text { ADF Test } \\
\text { Values } \\
\text { Asian Markets }\end{array}$} & \multirow[b]{2}{*}{$\begin{array}{l}\text { Statistical } \\
\text { Value }\end{array}$} & \multicolumn{4}{|c|}{ Test Critical Value } & \multirow{3}{*}{$\begin{array}{l}\text { Durbin } \\
\text { Watson Test }\end{array}$} & \multirow{3}{*}{ R-squared } \\
\hline & & $1 \%$ & $5 \%$ & $10 \%$ & Probability & & \\
\hline & & & & & & & \\
\hline China & -50.0744 & -3.43275 & -2.86249 & -2.56732 & 0.0000 & 1.999473 & 0.498652 \\
\hline India & -47.0739 & -3.43278 & -2.8625 & -2.56733 & 0.0000 & 1.994279 & 0.470982 \\
\hline Indonesia & -44.2398 & -3.43284 & -2.86252 & -2.56734 & 0.0000 & 2.000742 & 0.445299 \\
\hline Korea & -48.8085 & -3.43280 & -2.86251 & -2.56733 & 0.0000 & 1.999461 & 0.490353 \\
\hline Malaysia & -61.2444 & -3.43280 & -2.86251 & -2.56733 & 0.0000 & 2.015293 & 0.603143 \\
\hline Philippines & -43.8114 & -3.43283 & -2.86252 & -2.56734 & 0.0000 & 1.998165 & 0.440093 \\
\hline Taiwan & -46.9854 & -3.43280 & -2.86251 & -2.56733 & 0.0000 & 2.000115 & 0.472257 \\
\hline Thailand & -48.778 & -3.43284 & -2.86252 & -2.56734 & 0.0000 & 2.002598 & 0.493804 \\
\hline
\end{tabular}

Source: http://finance.yahoo.com/ and Computed using E-Views 7 Version.

\subsection{GARCH (1,1) Model for the Sample Indices of Asian Emerging Markets}

Table 3 shows the results of volatility using GARCH (1.1) model for daily share price returns of Asian emerging stock market indices during the study period from 01.01.2004 to 31.12.2013. As stated earlier, the sample emerging stock market indices in Asia included SSE Composite Index (China), S\&P CNX Nifty (India) Jakarta Composite Index (Indonesia), Korea Stock Exchange Index - KOPSI (Korea), FTSE Bursa Malaysia - KLSE 
(Malaysia), Philippine Stock Index (Philippine), Taiwan Stock Exchange Index -TWII (Taiwan) and Stock Exchange of Thailand Index (Thailand). From the above Table, it is clearly observed that the probability (P-Value) was zero at $99 \%$ confidence level. It is worth noting that values $(\alpha+\beta)$ for all sample emerging market indices were nearly to one. It is clear that the values $(\alpha+\beta)$ of five sample indices were 0.990508 (China), 0.990792 (India), 0.979936 (Indonesia), 0.988552 (Korea), 0.908718 (Malaysia), 0.968936 (Philippines), 0.989811 (Taiwan) and 0.936118 (Thailand). According to the analysis of GARCH Model, the $\alpha+\beta$ value of all the eight Asian emerging stock market indices were near to one. This indicates the fact that the returns data for all the eight indices of Asian emerging markets were highly volatile during the study period. Thus the Null Hypothesis (NH3), there is no volatility among the Indices of Emerging Stock Markets in Asia, is rejected.

The results of volatility (both $\alpha+\beta$ value) of all the eight Asian emerging market movements are shown in Figure 2. The above Chart clearly explains the high volatile in sample markets of Asia. It is to be noted that if the value of both $\alpha+\beta$ is to be close near to one, the above Chart represents the both high and low volatile stock markets in Asia. The index of India earned high volatility market with the value of 0.990792 , followed by India with a value of 0.990508 . The remaining six emerging market indices (in order) namely Taiwan (0.989811), Korea (0.98855), Indonesia (0.979936), Philippines (0.968936), Thailand (0.936118) and Malaysia (0.908718) were low volatility than India and China.

Table 3. Results of volatility using GARCH $(1,1)$ model for emerging Asian stock market indices returns during the study period from 01-01-2004 to 30-12-2013

\begin{tabular}{llllll}
\hline List of Asian Emerging Market Indices & $\mathbf{C}$ & $\boldsymbol{\alpha}$ & $\boldsymbol{\beta}$ & $\boldsymbol{\alpha}+\boldsymbol{\beta}$ & P Value \\
\hline China & 0.00000245 & 0.047538 & 0.94297 & $\mathbf{0 . 9 9 0 5 0 8}$ & 0.00000 \\
India & 0.00000347 & 0.110139 & 0.880653 & $\mathbf{0 . 9 9 0 7 9 2}$ & 0.00000 \\
Indonesia & 0.00000541 & 0.133653 & 0.846283 & 0.979936 & 0.00000 \\
Korea & 0.00000219 & 0.079937 & 0.908615 & 0.988552 & 0.00000 \\
Malaysia & 0.00000904 & 0.088121 & 0.820597 & 0.908718 & 0.00000 \\
Philippines & 0.00000683 & 0.147942 & 0.820994 & 0.968936 & 0.00000 \\
Taiwan & 0.00000176 & 0.068843 & 0.920968 & $\mathbf{0 . 9 8 9 8 1 1}$ & 0.00000 \\
Thailand & 0.00001190 & 0.105901 & 0.830217 & 0.936118 & 0.00000 \\
\hline
\end{tabular}

Source: http://finance.yahoo.com/ and Computed using E-Views 7 Version.

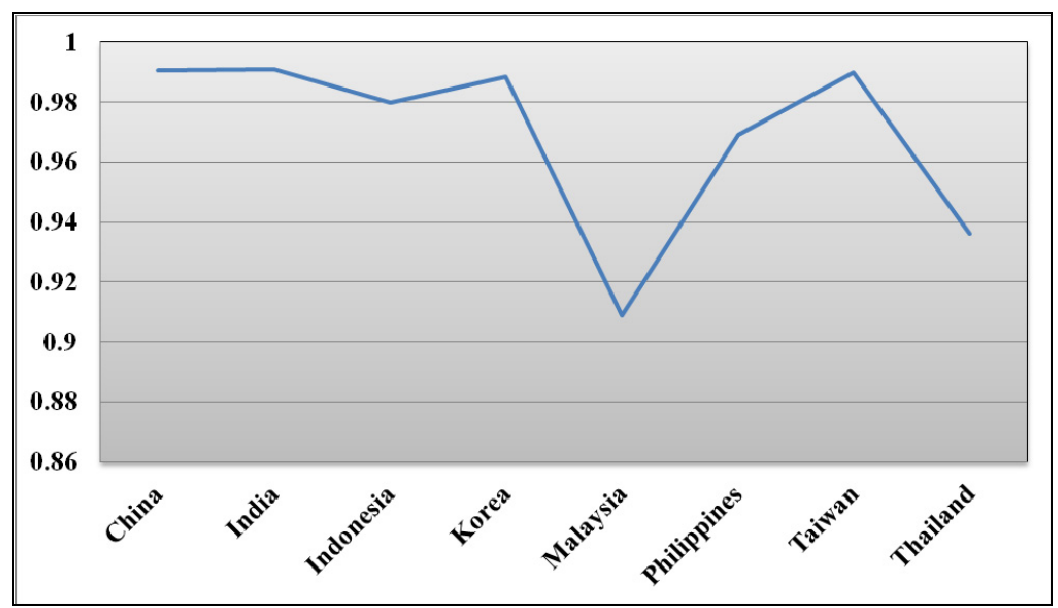

Figure 2. Results of Volatility $(\alpha+\beta)$ for Emerging Asian Stock Market Indices Returns during the study period from 01-01-2004 to 30-12-2013

Source: Data taken from Table-3 and Computed using MS office Excel - 2007. 


\subsection{Autocorrelation for the Sample Indices of Asian Emerging Markets}

Table 4. The results of autocorrelation for emerging Asian stock market indices returns during the study period from 01-01-2004 to 30-12-2013

\begin{tabular}{|c|c|c|c|c|c|c|c|c|}
\hline Lags & China & India & Indonesia & Korea & Malaysia & Philippines & Taiwan & Thailand \\
\hline 1 & -0.29314 & -0.21763 & -0.28503 & -0.28985 & -0.31099 & -0.27702 & -0.28430 & -0.25745 \\
\hline 2 & 0.04927 & -0.01703 & -0.04137 & 0.00600 & -0.00898 & 0.02246 & 0.01536 & -0.04047 \\
\hline 3 & -0.02883 & 0.02958 & 0.00267 & -0.00783 & 0.00631 & -0.01042 & -0.03445 & 0.01569 \\
\hline 4 & 0.01498 & 0.00998 & -0.00887 & -0.00857 & -0.01508 & -0.00098 & 0.00956 & -0.04181 \\
\hline 5 & 0.02150 & -0.00935 & 0.02417 & 0.00216 & 0.01732 & -0.00247 & 0.02693 & 0.01117 \\
\hline 6 & -0.01932 & 0.00159 & -0.00662 & -0.00992 & -0.01177 & -0.01193 & -0.05270 & -0.01143 \\
\hline 7 & 0.01865 & -0.00555 & -0.01923 & 0.01011 & 0.04268 & 0.00790 & 0.02536 & 0.00321 \\
\hline 8 & -0.01201 & -0.01540 & 0.00384 & -0.02882 & -0.01874 & 0.00515 & -0.03403 & 0.03209 \\
\hline 9 & -0.02185 & -0.01816 & -0.00770 & 0.03994 & -0.00564 & 0.01878 & 0.00857 & -0.01346 \\
\hline 10 & -0.01052 & -0.00548 & 0.02420 & -0.03957 & -0.00966 & -0.03819 & -0.00511 & 0.01904 \\
\hline 11 & 0.03104 & -0.00960 & -0.00480 & 0.00333 & -0.00125 & 0.04999 & 0.00175 & 0.00922 \\
\hline 12 & 0.03176 & 0.01684 & -0.00100 & 0.02059 & -0.00523 & -0.01788 & 0.00546 & 0.02085 \\
\hline 13 & -0.04334 & 0.00614 & -0.02897 & -0.00019 & 0.01220 & 0.02256 & 0.00734 & -0.00901 \\
\hline 14 & 0.05030 & 0.00172 & -0.01273 & -0.01522 & -0.01325 & 0.00027 & 0.01236 & -0.00795 \\
\hline 15 & -0.01036 & -0.01324 & 0.02609 & -0.00503 & 0.00033 & 0.02156 & -0.02413 & 0.00305 \\
\hline 16 & 0.00536 & -0.01429 & 0.00861 & 0.00353 & -0.00469 & 0.01848 & -0.01319 & 0.02121 \\
\hline 17 & 0.00967 & 0.01513 & -0.00641 & 0.00318 & -0.00002 & -0.01603 & 0.00986 & -0.00146 \\
\hline 18 & 0.01809 & -0.01393 & 0.00265 & 0.01997 & 0.02278 & 0.02111 & 0.00133 & 0.00274 \\
\hline 19 & -0.03363 & 0.01651 & -0.01474 & -0.00380 & 0.01984 & 0.00543 & -0.01686 & 0.01466 \\
\hline 20 & 0.03764 & -0.01441 & -0.00500 & 0.01822 & -0.02613 & -0.02859 & 0.05736 & -0.00237 \\
\hline 21 & -0.00062 & 0.00225 & 0.01810 & -0.01799 & 0.00242 & -0.00834 & -0.02350 & 0.01047 \\
\hline 22 & -0.03730 & 0.01257 & 0.01801 & -0.00588 & -0.01991 & -0.03000 & 0.00798 & -0.01744 \\
\hline 23 & 0.02381 & 0.01977 & -0.01367 & 0.01901 & -0.00588 & 0.04288 & -0.00662 & 0.01167 \\
\hline 24 & 0.00882 & -0.02567 & -0.00951 & -0.02431 & 0.01136 & -0.00882 & -0.03581 & 0.03658 \\
\hline
\end{tabular}

Source: $\mathrm{http} / /$ finance.yahoo.com/ and Computed using SPSS 21 Version.

The result of autocorrelation for daily returns of eight emerging market Indices in Asia (namely, SSE Composite Index (China), S\&P CNX Nifty (India), Jakarta Composite Index (Indonesia), Korea Stock Exchange Index KOPSI (Korea), FTSE Bursa Malaysia - KLSE (Malaysia), Philippine Stock Index (Philippine), Taiwan Stock Exchange Index -TWII (Taiwan) and Stock Exchange of Thailand Index (Thailand)) during the study period from 01.01.2004 to 31.12.2013, are presented in Table 4. It is noted that totally 24 lags were used for the analysis of this study during the study period. According to the analysis of autocorrelation coefficients, there was positive the values of $0.04927,0.01498,0.0215,0.01865,0.03104,0.03176,0.0503,0.00536,0.00967,0.01809$, $0.03764,0.02381$ and 0.00882 , for china at $2^{\text {nd }}, 4^{\text {th }}, 5^{\text {th }}, 7^{\text {th }}, 11^{\text {th }}, 12^{\text {th }}, 14^{\text {th }}, 16^{\text {th }}, 17^{\text {th }}, 18^{\text {th }}, 20^{\text {th }}, 23^{\text {rd }}$ and $24^{\text {th }}$ lags, respectively. It is to be noted that out of 24 lags, thirteen lags were recorded passive values in respect of China. The analysis of autocorrelation for India clearly shows that out of 24 lags, only 10 lags earned positive values, i.e. for lags $3^{\text {rd }}, 4^{\text {th }}, 6^{\text {th }}, 12^{\text {th }}, 13^{\text {th }}, 14^{\text {th }}, 19^{\text {th }}, 21^{\text {st }}, 22^{\text {nd }}$ and $23^{\text {rd }}$ lags, with the values of $0.02958,0.00998,0.00159$, $0.01684,0.00614,0.00172,0.01651,0.00225,0.01257$ and 0.01977 , respectively. The remaining 14 lags recorded negative values. It is clear from the analysis of autocorrelation in respect of that Indonesia that out of 24 lags, only 9 lags recorded positive values, i.e. $0.00267,0.02417,0.00384,0.0242,0.02609,0.00861,0.00265$, 0.0181 and 0.01801 , for $3^{\text {rd }}, 5^{\text {th }}, 8^{\text {th }}, 10^{\text {th }}, 15^{\text {th }}, 16^{\text {th }}, 18^{\text {th }}, 21^{\text {st }}$ and $22^{\text {nd }}$ lags, respectively. The remaining 15 lags recorded negatives values during the study period. In respect of Korea the analysis of autocorrelation shows that out of 24 lags, 11 lags recorded positive values, i.e. 0.006, 0.00216, 0.01011, 0.03994, 0.00333, 0.02059, $0.00353,0.00318,0.01997,0.01822$ and 0.01901 , for $2^{\text {nd }}, 5^{\text {th }}, 7^{\text {th }}, 9^{\text {th }}, 11^{\text {th }}, 12^{\text {th }}, 16^{\text {th }}, 17^{\text {th }}, 18^{\text {th }}, 20^{\text {th }}$ and $23^{\text {rd }}$ lags, respectively. The remaining 13 lags in respect of Korea recorded negative values. It is to be noted from the analysis of autocorrelation for Malaysia that out of 24 lags, only 9 lags earned positive values, i.e. 0.00631 , $0.01732,0.04268,0.0122,0.00033,0.02278,0.01984,0.00242$ and 0.01136 , for $3^{\text {rd }}, 5^{\text {th }}, 7^{\text {th }}, 13^{\text {th }}, 15^{\text {th }}, 18^{\text {th }}, 19^{\text {th }}$, $21^{\text {st }}$, and $24^{\text {th }}$ lags, respectively. The remaining 15 lags recorded negative values. The test of autocorrelation in respects of Philippines reveals the fact that out of 24 lags, $50 \%$ (i.e. 12 of the lags) earned positive values i.e. 
$0.02246,0.0079,0.00515,0.01878,0.04999,0.02256,0.00027,0.02156,0.01848,0.02111,0.00543$ and 0.04288 , at $2^{\text {nd }}, 7^{\text {th }}, 8^{\text {th }}, 9^{\text {th }}, 11^{\text {th }}, 13^{\text {th }}, 14^{\text {th }}, 15^{\text {th }}, 16^{\text {th }}, 18^{\text {th }}, 19^{\text {th }}$ and $23^{\text {rd }}$ lags, respectively. The remaining 12 lags recorded negative values. It is significant to note from the results of autocorrelation for Taiwan that more than $50 \%$ of the lags (i.e. $13 \mathrm{lags}$ ) recorded positive values, i.e. $0.01536,0.00956,0.02693,0.02536,0.00857$, $0.00175,0.00546,0.00734,0.01236,0.00986,0.00133,0.05736$ and 0.00798 , at $2^{\text {nd }}, 4^{\text {th }}, 5^{\text {th }}, 7^{\text {th }}, 9^{\text {th }}, 11^{\text {th }}, 12^{\text {th }}$, $12^{\text {th }}, 13^{\text {th }}, 14^{\text {th }}, 17^{\text {th }}, 18,20^{\text {th }}$ and $22^{\text {nd }}$ lags, respectively. The remaining 11 lags recorded negative values. The analysis of autocorrelation for Thailand shows that out of 24 lags, 13 earned positive values. The lags like $3^{\text {rd }}, 5^{\text {th }}$, $7^{\text {th }}, 8^{\text {th }}, 10^{\text {th }}, 11^{\text {th }}, 12^{\text {th }}, 15^{\text {th }}, 16^{\text {th }}, 18^{\text {th }}, 19^{\text {th }}, 21^{\text {st }}$ and $24^{\text {th }}$ earned values of $0.01569,0.01117,0.00321,0.03209$, $0.01904,0.00922,0.02085,0.00305,0.02121,0.00274,0.01466,0.01047$ and 0.03658 , respectively. The remaining 11 lags recorded negative values during the sample study period. The overall results of Autocorrelation Function shows as given in above Table that eight Asian emerging stock market indices followed significant autocorrelation during the study period. Hence, Null Hypothesis (NH4), there is no Weak form Efficiency among the indices of Emerging Stock Markets in Asia, is rejected.

\subsection{Runs Test for the Sample Indices of Asian Emerging Markets}

The results of Runs Test in respect of eight emerging Asian sample stock market indices during the study period from $01^{\text {st }}$ January 2004 to $31^{\text {st }}$ December 2013 are presented in Table 5. It is to be noted the value of $Z$ statistic is calculated using Total Runs and Observations. According to Sharma and Kennedy (1977), when the Z Statistic value is greater than or equal to \pm 1.96 , the null hypothesis is to be rejected at $5 \%$ of significance. This study also followed above norms. The actual Z Statistics values of sample indices are -2.324187 (India), -2.044677 (Indonesia), -3.400457 (Malaysia) and -4.632167071 (Philippines) and these values were also greater than \pm 1.96 . But, the Probability Value of the four sample indices are 0.020115 (India), 0.04088 (Indonesia), 0.00067 (Malaysia) and 0.000004 (Philippines) and these values were significant as the value was less than 0.05 . This indicates the fact that out of eight indices (Shanghai Stock Exchange Composite Index - China, NSE Nifty-India, Jakarta Composite Index -Indonesia, Kospi Index -Korea, KLSE -Malaysia, Philippine stock Index-Philippines, Taiwan Stock Exchange Index-Taiwan, and Stock Exchange of Thailand Index-Thailand), the four sample indices (NSE Nifty-India, Jakarta Composite Index -Indonesia, KLSE -Malaysia and Philippine stock Index-Philippines) in Asian emerging markets were randomly distributed during the study period, i.e. the past index prices were normally reflected in the future price during the study period. The $\mathrm{Z}$ statistics values of the other four indices are, -1.35378 (China), 0.74328 (Korea), -0.16100 (Taiwan) and -1.8216 (Thailand) and these values were not randomly distributed i.e. the past index prices were not reflected in the future price during the study period.

The overall analysis of Runs test (Z Statistics and Probability Values) for eight emerging Asian stock market indices revealed that $50 \%$ of the indices i.e. four indices (NSE Nifty-India, Jakarta Composite Index -Indonesia, KLSE -Malaysia and Philippine stock Index-Philippines) under Asian emerging stock markets were randomly distributed at $95 \%$ confidence level. The remaining four emerging markets indices (Shanghai Stock Exchange Composite Index - China, Kospi Index -Korea, TSEC weighted Index-Taiwan, and SET Index-Thailand) under Asian region were not randomly distributed at 5\% significance level. Hence the Null Hypothesis (NH5), namely, there is no random distribution among the indices of Emerging Stock Markets in Asia, is partially accepted.

Table 5. Results of runs test for emerging Asian stock market indices returns during the study period from 01-01-2004 to 30-12-2013

\begin{tabular}{ccccc}
\hline $\begin{array}{c}\text { List of Asian Emerging } \\
\text { Market Indices }\end{array}$ & $\begin{array}{c}\text { Number of } \\
\text { Runs }\end{array}$ & $\begin{array}{c}\text { Number of } \\
\text { Observations }\end{array}$ & $\mathrm{Z}$ & Asymp. Sig. (2-tailed)a \\
\hline China & 1229 & 2524 & -1.353786944 & 0.17580436 \\
India & 1189 & 2492 & $\mathbf{- 2 . 3 2 4 1 8 7 4 9 6}$ & $\mathbf{0 . 0 2 0 1 1 5 4 4 7}$ \\
Indonesia & 1171 & 2441 & $\mathbf{- 2 . 0 4 4 6 7 7 4 5 5}$ & $\mathbf{0 . 0 4 0 8 8 6 6 6 8}$ \\
Korea & 1259 & 2479 & 0.743285933 & 0.457308586 \\
Malaysia & 1152 & 2471 & $\mathbf{- 3 . 4 0 0 4 5 7 0 5 8}$ & $\mathbf{0 . 0 0 0 6 7 2 7 3 3}$ \\
Philippines & 1109 & 2445 & $\mathbf{- 4 . 6 3 2 1 6 7 0 7 1}$ & $\mathbf{0 . 0 0 0 0 0 4 0 0 0}$ \\
Taiwan & 1232 & 2470 & -0.161001335 & 0.872092349 \\
Thailand & 1177 & 2442 & -1.82162365 & 0.06851211 \\
\hline
\end{tabular}

Source: http://finance.yahoo.com/ and Computed using SPSS 21 Version. 


\section{Conclusions of the Study}

This paper examines market efficiency in the emerging stock markets like China, India, Indonesia, Korea, Malaysia, Philippines, Taiwan and Thailand. The Unit root tests, Auto Correlation, GARCH (1.1) Model and Runs test were used to test the efficiency of eight emerging stock markets in Asia. The study focused emerging market indices namely, SSE Composite Index (SSE) - China, S\&P CNX Nifty - India, Jakarta Composite Index (JKSE) - Indonesia, Korea Stock Exchange Index (KOPSI) - Korea, FTSE Bursa Malaysia (KLSE) - Malaysia, Philippine Stock Index - Philippines, Taiwan Stock Exchange (TWII) - Taiwan and Stock Exchange of Thailand Index - Thailand. The daily closing returns of all sample indices varied from 56.563 to 207.485 percent during the study period. But, the average daily return of Indonesia was higher than other emerging Asian stock markets, with 207.485 percent, followed by Philippine Stock Index with 163.5705 percent. Taiwan recorded the least return value of 56.563 percent.

According to the ADF results, all the eight indices were stationery at $1 \%, 5 \%$ and $10 \%$ significance levels during the study period. The results of GARCH $(1,1)$ Model shows that the Volatility, the index of S\&P CNX Nifty India (0.990792) recorded highly volatile, followed by SSE Composite Index - China (0.990508) provided next highest volatile index during the study period. The remaining six indices were lower than the India and China. According to the results of Autocorrelation to test the market efficiency, all the eight indices under Asian region were significant at $95 \%$ confidence level. The result of Runs Test shows that the four indices namely, India, Indonesia, Malaysia and Philippines were highly random distribution at 95\% confidence level. According to $\mathrm{P}-$ Value and $\mathrm{Z}$ - Statistics, the remaining four indices namely, China, Korea, Taiwan and Thailand were not significant and also did not random distribution.

The results of this study, particularly those of the econometric tests, like ADF, GARCH $(1,1)$ Model, Autocorrelation and Runs Test have provided important information for the retail investors and Governments and Policy regulators of the above eight sample countries. The relationships among the sample indices may be used by national as well as global investors to forecast the efficiency of emerging markets in order to invest in profitable stock markets in Asia. Investors are advised to invest in four markets, namely, the emerging markets of India, Indonesia, Malaysia and Philippines that were highly efficient during the study period. The government, policy makers and other stake holders can take appropriate steps to improve the corporate disclosure practices in an appropriate manner so that the stock market index prices instantly reflect all available information.

\section{References}

Angela, N. (2000). Volatility spillover effects from Japan and the US to the Pacific-Basin. Journal of International Money and Finance, 19, 207-233. http://dx.doi.org/10.1016/S0261-5606(00)00006-1

Aymen Ben Rejeb and Adel Boughrara. (2013). Financial liberalization and stock markets efficiency: New evidence from emerging economies. Emerging Markets Review, 17, 186-208. http://dx.doi.org/10.1016/j. ememar.2013.09.001

Blitz, D., Pang, J., \& Vliet, P. van. (2013). The volatility effect in emerging markets. Emerging Markets Review, 16, 31-45. http://dx.doi.org/10.1016/j.ememar.2013.02.004

Choudhry, T. (1996). Stock Market Volatility and the Crash of 1987: Evidence from Six Emerging Markets. Journal of International Money and Finance, 15(6), 969-981. http://dx.doi.org/10.1016/S0261-5606 (96)00036-8

Cifarellia, G., \& Paladino, G. (2005). Volatility linkages across three major equity markets: A financial arbitrage approach. Journal of International Money and Finance, 24, 413-439. http://dx.doi.org/10.1016/j.jimonfin. 2005.01.005

Cooray, A. V. (2007). The efficiency of emerging stock markets: Empirical evidence from the South Asian region. Journal of Developing Areas, 41(1), 171-183. Retrieved from http://ro.uow.edu.au/commpapers/564

Dimitrakopoulos, D. N., Kavussanos, M. G., \& Spyrou, S. I. (2010). Value at risk models for volatile emerging markets equity portfolios. The Quarterly Review of Economics and Finance, 50, 515-526. http://dx.doi.org/10.1016/j.qref.2010.06.006

Eizaguirre, J. C., Biscarri, J. G., \& Hidalgo, F. P. de G. (2004). Structural changes in volatility and stock market development: Evidence for Spain. Journal of Banking \& Finance, 28, 1745-1773. http://dx.doi.org/10.1016/ j.jbankfin.2003.06.004

Gil-Alana, L. A., Shittu, O. I. \& Yaya, O. S. (2014). On the persistence and volatility in European, American and Asian stocks bull and bear markets. Journal of International Money and Finance, 40, 149-162. 
http://dx.doi.org/10.1016/j.jimonfin.2012.12.002

Jaleel, F. M., \& Samarakoon, L. P. (2009). Stock market liberalization and return volatility: Evidence from the emerging market of Sri Lanka. Journal of Multinational Financial Management, 19, 409-423. http://dx.doi.org/10.1016/j.mulfin.2009.07.006

Lagoarde-Segot, T., \& Lucey, B. M. (2008). Efficiency in emerging markets-Evidence from the MENA region. Journal of International Financial Markets, Institutions and Money, 18, 94-105. http://dx.doi.org/10.1016/ j.intfin.2006.06.003

Lim, C. M., \& Sek, S. K. (2013). Comparing the performances of GARCH-type models in capturing the stock market volatility in Malaysia. Procedia Economics and Finance, 5, 478-487. http://dx.doi.org/10.1016/ S2212-5671(13)00056-7

Lingaraja, K., Selvam, M., \& Vasanth. V. (2014). Co Movements and Inter-Linkages among Emerging and Developed Stock Markets in Asia with Reference to Singapore Stock Exchange. International Research Journal of Finance and Economics, 122, 102-120.

Nartea, G. V., \& Wu, J. (2013). Is there a volatility effect in the Hong Kong stock market? Pacific-Basin Finance Journal, 25, 119-135. http://dx.doi.org/10.1016/j.pacfin.2013.07.004

Plesoianua, A., Todea, A., \& Capusan, R. (2012). The informational efficiency of the Romanian stock market: evidence from fractal analysis. Procedia Economics and Finance, 3, 111-118. http://dx.doi.org/10.1016/S2212-5671(12)00128-1

Queensly Jeyanthi, B. J., Albert, M., \& William, S. J. (2009). An Empirical Analysis of Dynamic Linkages: A Case of India, Japan, Singapore and USA Stock Markets. SMART Journal of Business Management Studies, 5(1), 58-64.

Rejichi, I. Z., \& Aloui, C. (2012). Hurst exponent behavior and assessment of the MENA stock markets efficiency. Research in International Business and Finance, 26, 353-370. http://dx.doi.org/10.1016/j.ribaf. 2012.01.005

Selvam, M., Raja, M., \& Yazh Mozli, P. (2007). Forecasting the Time Volatility of Emerging Asian Stock Market Index. Asia-PacificBusiness Review, 8(2), 27-37. http://dx.doi.org/10.1177/097324700700300205

Sharma, J. L., \& Kennedy, R. E. (1977). A Comparative Analysis of Stock Price Behavior on the Bombay, London and New York Stock Exchanges. Journal of Financial and Quantitative Analysis, September, 183-190.

Syed Aun R. R., Dewandaru, G., Bacha, O. I., \& Masih, M. (2014). An analysis of stock market efficiency: Developed vs Islamic stock markets using MF-DFA. Physica A, 407, 86-99. http://dx.doi.org/10.1016/ j.physa.2014.03.091

Wang, P., \& Theobald, M. (2008). Regime-switching volatility of six East Asian emerging markets. Research in International Business and Finance, 22, 267-283. http://dx.doi.org/10.1016/j.ribaf.2007.07.001

\section{Notes}

Note 1. http://www.msci.com/products/indexes/tools/index_country_membership/emerging_markets.html

Note 2. http://www.fncentral.com/401k/tips/money/moneyman_112299.html

\section{Copyrights}

Copyright for this article is retained by the author(s), with first publication rights granted to the journal.

This is an open-access article distributed under the terms and conditions of the Creative Commons Attribution license (http://creativecommons.org/licenses/by/3.0/). 